\title{
(JIPD)
}

Jurnal Inovasi Pendidikan Dasar

Vol. 4, No. 1, Bulan Januari Tahun 2020, Hal. 46-50

E-ISSN: 2598-408X, P-ISSN: 2541-0202

http://unikastpaulus.ac.id/jurnal/index.php/jipd

\section{PENGARUH PEMANFAATAN PERANGKAT TEKNOLOGI INFORMASI DAN KOMUNIKASI TERHADAP PENINGKATAN KOMPETENSI PROFESIONAL GURU SEKOLAH DASAR}

\author{
Yohannes Marryono Jamun ${ }^{1}$, Zephisius Rudiyanto Eso Ntelok ${ }^{2}$, Rudolof Ngalu ${ }^{3}$ \\ ${ }^{123}$ Program Studi PGSD, FKIP, Unversitas Katolik Indonesia Santu Paulus Ruteng, \\ Jl. Ahmad Yani, No.10 Ruteng, 86508 \\ e-mail: ryojamun@gmail.com
}

Diterima: 11 Januari 2020 , Direvisi: 15 Januari 2020, Diterbitkan: 31 Januari 2020

\begin{abstract}
The 4.0 industrial revolution era requires teachers to have a number of characteristics to arrange an appropriate learning administration, be able to design learning media by utilizing Information and Communication Technology (ICT) devices wisely, effectively, competently and professionally. However there are still many problems that hamper the implementation of teacher professional competence in the field of ICT. This study aims to determine whether there is a positive or significant effect between the use of ICT devices on improving teacher professional competence. This type of research is correlational with a quantitative approach. The population of this study were35 elementary school teachers. Data were collected through questionnaire technique. The results of this study indicate that there is a positive and significant influence between the use of ICT devices on increasing the professional competence of group of Elementary School Teachers, with 0.60correlation coefficient. $T$ test results show that $t_{\text {count }}>t_{\text {table }}$ which is $4.31>2.235$. The contribution of ICT tools use to the improvement ofprofessional competence of group of elementary school teachers at Ruteng is $36.05 \%$ and $63.95 \%$ is influenced by other variables which were not examined by researchers.
\end{abstract}

Keywords: ICT devices, teacher professional competence

\begin{abstract}
Abstrak: Era revolusi industri 4.0 menuntut guru agar mempunyai sejumlah karakteristik untuk menyusun administrasi belajar yang tepat, mampu mendesain media pembelajaran dengan memanfaatkan perangkat Teknologi Informasi dan Komunikasi (TIK) yang ada secara arif, efektif, kompeten dan profesional. Untuk sampai pada tujuan tersebut masih banyak ditemukan masalah yang menghambat pelaksanaan kompetensi profesional guru dalam bidang TIK.Penelitian ini bertujuan untuk mengetahui apakah terdapat pengaruh yang positif atau signifikan antara pemanfaatan perangkat TIK terhadap peningkatan kompetensi profesional guru. Jenis penelitian ini adalah korelasional dengan pendekatan kuantitatif. Populasi dalam penelitian adalah semua guru Se-Kecamatan Ruteng. Sampel sejumlah 35 orang guru. Teknik pengumpulan data dilakukan menggunakan kuesioner (angket).Hasil penelitian ini menunjukan bahwa terdapat pengaruh yang positif dan signifikan antara pemanfaatan perangkat TIK terhadap peningkatan kompetensi profesional guru SD SeKecamatan Ruteng, dengan koefisien korelasi sebesar 0,60. Hasil uji $t$ menunjukan $t_{\text {hitung }}>t_{\text {tabel }}$ yaitu 4,31>2,235. Besar sumbangan variabel pemanfaatan perangkat TIK terhadap peningkatan kompetensi profesional guru SD Se-Kecamatan Ruteng sebesar 36,05\% dan sisanya 63,95\% dipengaruhi variabel lain yang tidak diteliti oleh peneliti.
\end{abstract}

Kata Kunci: perangkat TIK, kompetensi profesional guru

\section{PENDAHULUAN}

Eksistensi guru yang kompeten dan profesional merupakan syarat mutlak hadirnya sistem dan praktik pendidikan yang berkualitas. Hampir semua bangsa di dunia ini selalu mengembangkan kebijakan yang mendorong keberadaan guru yang berkualitas. Salah satu kebijakan yang dikembangkan oleh pemerintah di banyak negara adalah dengan menempatkan bidang pendidikan sebagai bidang yang perlu 
mendapat perhatian khusus dengan menyediakan hardware \&software yang memadai (Rusman dkk, 2011: 18). Hal ini menjadikan Teknologi Informsi dan Komunikasi (TIK) begitu penting dalam implementasi konsep tersebut. Pertanyaanya sudahkah semua guru menerapkan kompetensi ini dalam praktek pembelajaran mereka.

Saat ini masalah kompetensi guru di Indonesia khususnya guru Sekolah Dasar belum sepenuhnya memanfaatkan TIK. Contohnya guru-guru SD di Kecamatan Ruteng. Ketersediaan perangkat TIK memang sudah memadai tetapi taraf pemanfaatannya masih pada tingkat 3 Defined Process, yaitu prosedur dalam penggunaan fasilitas TIK sudah terstandariasi, namun kegiatannya masih tergolong minim.Prosedur tersebut juga tidak dibuat rumit untuk memudahkan individu dan hanya sebagai bentuk formalitas belaka, (Gita, 2002: 4). Salah satu indikator guru profesional dan kompeten adalah guru yang mampu beradaptasi dengan perkembangan keilmuan yang hari demi hari semakin canggih dengan cara penguasaan Teknologi Informasi dan Komunikasi (TIK). Hal ini merupakansalah satu visi yang harus dipahami dan aplikasikan oleh semua guru di era milenial.

Visi yang ada justru membuat guru-guru di Kecamatan Rutengsemakin khawatir dengan kompetensi berteknologi yang dimiliki. kemampuan guru menguasai teknologi tergolong lemah karena sumber daya manusia untuk mengolahnya terbatas. Bahkan masih ada guru yang sama sekali tidak bisa memanfaatkan aplikasi microsoft office secara maksimal. Seperti kesusahan dalam mengetik administrasi belajar dengan baik dan benar, merekap nilai siswa menggunakan rumusyang tersedia di Ms. Excel, mendownload dan menginstal aplikasi pembelajaran berbasis TIK. Selain itu, ditemukan guru-guru mengalami kendala menginput nilai siswa ke dalam aplikasi rapor K-13, ini disebabkan oleh caramanual yang ada pada sistem kurikulum lama sehingga sulit beradabtasi dengan kurikulum berbasis teknologi.

Revolusi teknologi informasi telah mengubah cara kerja manusia mulai dari cara berkomunikasi, cara memproduksi, cara mengkoordinasi, cara berpikir, hingga cara belajar mengajar. Mulai dari kelengkapan silabus, rencana pelaksanaan pembelajaran, penggunaan metode, media yang mendukung, serta pengelolaan kelas yang kondusif. Hal ini menuntut guru untuk peka terhadap perkembangan IPTEK yang ada agar dapat meningkatkan kreatifitas, mengembangkan kegiatan belajar yang menyenangkan. Sebab pembelajaran yang kreatif dan menyenangkan merupakan hal yang sangat penting, karena dapat membantu siswa untuk berhasil dalam pembelajaran, menciptakan solusi dalam memecahkan masalah,mempengaruhi kehidupan siswa, serta menimbulkan rasa senang dan puas (Rusti, dkk, 2014: 52).

Terlepas dari itu, diuraikan beberapa rincian informasi terkait kelengkapan fasilitas TIK di SDI Kusu. Sekolah ini menyediakan perangkat TIK 6 (enam) unit diantaranya yaitu Laptop 3(tiga) unit dan Printer 3(tiga) unit. Memiliki jaringan Wi-Fidengan kualitas signal 4G. Selain itu, masing-masing guru memiliki laptop juga smartphone. Hal serupa berlaku juga untuk SDI Til, sekolah ini memiliki perangkat teknologi yaitu laptop berjumlah 3 (tiga) unit dan printer 3 (tiga) unit. Semua guru menggunakan smartphone dan laptop pribadi dengan akses jaringan 4G sertajaringan Wi-Fiyang terbilang sangat canggih. Sedangkan di SDK La'o Ngkor, sekolah menyediakan perangkat teknologi berjumlah 9 (sembilan) unit diantaranyaPC 2 (dua) unit, laptop 3 (tiga) unit, dan printer 4 (empat) unit. Untuk hal-hal teknis lain seperti jaringanWi-Fi, sumber daya listrik dan signal telekomunikasi sama kondisinya dengan kedua sekolah yang sudah disebutkan di atas.Sebagai informasi tambahan yang diperoleh peneliti, ketiga sekolah yang dibahas dalam gugus ini akan menerima sumbangan perangkat teknologi dari pemerintah dengan porsi yang lebih banyak dalam waktu dekat.Tetapi di balik pemberian tersebut, pemerintah menuntut para guru untuk lebih meningkatkan profesionalismenya dengan penguasaan kompetensi yang dimilikinya.

Dari kenyataan yang dipaparkan sebelumnya, maka dapat diidentifikasikan masalah, antara lain: 1) belum maksimalnya pemanfaatan teknologi yang disebabkan olehminimnya pengetahuan dan keterampilan guru dalam mengoperasikan perangkat TIK yang telah tersedia; 2) kompetensi guru yang masih terikat pada sistem kurikulum lama. Sulit beradaptasi dengan alur pendidikan di era revolusi industry 4.0 yang menuntut guru untuk lebih kreatif, inovatif dan professional; 3) belum maksimalnya persiapan administrasi sekolah berbasis TIK oleh guru. Berdasarkan uraian di atas, adapun tujuan dari penelitian ini adalah sebagai berikut: Untuk mengetahui pengaruh 
pemanfaatan perangkat TIK terhadap peningkatan kompetensi profesional Guru SD.

\section{METODE}

Penelitian ini adalah jenis penelitian korelasional. Penelitian korelasi ini terdapat dua variabel yang akan diteliti yaitu variabel bebas dan variabel terikat,varibel bebasnya adalah Pemanfaatan Perangkat TIK sedangkan variabel terikatnya adalah Peningkatan Kompetensi Profesional Guru. Arikunto (2013:4) menjelaskan bahwa penelitian korelasional adalah penelitian yang dilakukan olehpeneliti untuk mengetahui tingkat hubungan antara dua variabel atau lebih, tanpa melakukan perubahan, tambahan atau manipulasi terhadap data-data yang sudah ada. Hubungan antara satu dengan beberapa variabel lain dinyatakan dengan besarnya koefesien korelasi dan signifikansi secara statistik. Penelitian ini menggunakan model analisis regresi. Model analisis regresi dilakukan atas dasar pertimbangan bahwa variabel-variabel yang diteliti memiliki hubungan yang fungsional.

Populasi dalam penelitian adalah semua guru Se-Kecamatan Ruteng. Sampel sejumlah 35 orang guru, sampel ditentukan menggunakan teknik purposive.Untuk memperoleh data yang diperlukan, penelitian ini menggunakan teknik non tes, melalui pengisian angket yang berjumlah 20 butir pernyataan dengan jumlah responden 35 guru. Setiap pernyataan memiliki 5 alternatif jawaban (sangat sering, sering, kadang-kadang, jarang, dan tidak pernah). Agar instrumen penelitian ini layak digunakan sebagai alat pengumpulan data, maka terlebih dahulu harus diujicobakan melalui uji validitas dan uji reliabilitas instrumen. Setelah pernyataanpernyataan yang valid dan sudah diujirealiabilitasnya dipilah, maka pernyataanpernyataan tersebut dimanfaatkan oleh peneliti sebagai instrumen atau alat test dalam penelitian. Teknik analisis data yang digunakan dalam penelitian ini adalah Analisis Statistik Deskriptif (Mean, Histogram, Distribusi Frekuensi). Statistik deskriptif dalam penelitian ini menggunakan rumus mean, standar deviasi, distribusi frekuensi, dan histogram. Pengujian homogenitas varians menggunakan uji $\mathrm{F}$ dengan rumus sebagai berikut:

$$
\begin{aligned}
& \qquad F=\frac{\text { varian terbesar }}{\text { varian terkecil }} \\
& \text { Kelompok-kelompok yang dibandingkan } \\
& \text { mempunyai varians yang homogen apabila }
\end{aligned}
$$

$\mathrm{F}_{\text {hitung }}<\mathrm{F}_{\text {tabel }}$ pada taraf kesalahan tertentu, yakni pada taraf signifikan $(\alpha)$ adalah 0,05 atau $5 \%$.

\section{Uji Normalitas}

Pengujian normalitas data dengan menggunakan uji Liliefors dengan mengurutkan selisih dari yang terkecil sampai terbesar dan menentukan frekuensi dari masing-masing data. Dengan kriteria pengujiannya yaitu jika $\mathrm{L}_{\text {hitung }}<$ $\mathrm{L}_{\text {tabel }}$ untuk taraf signifikan 5\% maka hipotesis nol yang menyatakan bahwa data berasal dari populasi yang berdistribusi normal dapat diterima.

\section{Uji Hipotesis}

Analisis data yang digunakan peneliti adalah dengan menggunakan uji tindependent. Rumus uji $t$ Hipotesis yang digunakan dalam penelitian ini adalah Korelasi Product Moment Karl Person. Korelasi Pearson Product Moment ini berfungsi untuk mengetahui hubungan antara variabel bebas (independent variabel) dengan variabel terikat (dependent variabel). Menurut Riduwan (2012: 227), rumus Korelasi Pearson Product Moment adalah sebagai berikut:

$$
r_{X, Y}=\frac{n \cdot\left(\sum X_{i} Y\right)-\left(\sum X_{i}\right) \cdot\left(\sum Y\right)}{\sqrt{\left\{n \cdot \sum X_{i}^{2}-\left(\sum X_{i}\right)^{2}\right\} \cdot\left\{n \cdot \sum Y^{2}-\left(\sum Y\right)^{2}\right\}}}
$$

Jika $r_{x_{i} y}$ (nilai koefisien korelasi) bertanda positif, maka korelasi tersebut positif. Sebaliknya, jikar $r_{x_{i} y}$ (nilai koefisien korelasi) bertanda negatif, maka korelasi tersebut negatif.

\section{HASIL DAN PEMBAHASAN}

\section{Kompetensi Profesional}

Dari hasil uji validitas 20 pernyataan variabel peningkatan kompetensi profesional guru, yang valid adalah 17 sedangkan 3 pernyataan dinyatakan drop. Data yang valid merupakan data penelitian. Rekapitulasi Perhitungan skor data penelitian kompetensi profesional guru diperoleh skor terbesar adalah 85 , skor terkecil 51, rentangan 34 , banyak kelasnya 6 , panjang kelas 6 , mean 71,5 dan standar deviasi 9,38. Secara ringkas hasil perhitungan untuk menentukan tabel distribusi frekuensi data peningkatan kompetensi profesional guru disajikan pada tabel di bawah ini; 
Tabel 1. Distribusi Frekwensi Data Variabel (Y)

\begin{tabular}{|c|c|c|c|c|c|c|}
\hline $\begin{array}{c}\text { Kelas } \\
\text { Interval }\end{array}$ & $\begin{array}{c}\text { Nilai } \\
\text { Tengah }\end{array}$ & $\begin{array}{c}\text { Batas } \\
\text { Bawah }\end{array}$ & $\begin{array}{c}\text { Batas } \\
\text { Atas }\end{array}$ & $\begin{array}{c}\text { Frekuensi } \\
\text { Absolut }\end{array}$ & $\begin{array}{c}\text { Frekuensi } \\
\text { Kumulatif }\end{array}$ & $\begin{array}{c}\text { Frekuensi } \\
\text { Relatif }\end{array}$ \\
\hline $51-56$ & 53,5 & 50,5 & 56,5 & 2 & 2 & $5,7 \%$ \\
\hline $57-62$ & 59,5 & 56,5 & 62,5 & 1 & 3 & $2,9 \%$ \\
\hline $63-68$ & 65,5 & 62,5 & 68,5 & 8 & 11 & $22,9 \%$ \\
\hline $69-74$ & 72,5 & 68,5 & 74,5 & 8 & 19 & $22,9 \%$ \\
\hline $75-80$ & 77,5 & 74,5 & 80,5 & 5 & 24 & $14,3 \%$ \\
\hline $81-86$ & 83,5 & 80,5 & 86,5 & 11 & 35 & $31,4 \%$ \\
\hline Jumlah & 412 & 395 & 429 & 35 & & $100,0 \%$ \\
\hline
\end{tabular}

\section{Pemanfaatan Perangkat TIK}

Dari hasil uji validitas 20 pernyataan variabel peningkatan kompetensi profesional guru, yang valid adalah 17 sedangkan 3 pernyataan dinyatakan drop. Data yang valid merupakan data penelitian. Perhitungan skor variabel pemanfaatan perangkat TIK diperoleh dengan jumlah skor terbesar adalah 85 , skor terkecil 52, rentangan 33, banyak kelasnya 6 , panjang kelas 6 , mean 71,4 dan standar deviasi 9,19 . Secara ringkas hasil perhitungan untuk menentukan tabel distribusi frekuensi data pemanfaatan TIK disajikan pada tabel di bawah ini;

Tabel 2. Distribusi Frekuensi Variabel

\section{(X)}

\begin{tabular}{|c|c|c|c|c|c|c|}
\hline $\begin{array}{c}\text { Kelas } \\
\text { Interval }\end{array}$ & $\begin{array}{c}\text { Nilai } \\
\text { Tengah }\end{array}$ & $\begin{array}{c}\text { Batas } \\
\text { Bawah }\end{array}$ & $\begin{array}{c}\text { Batas } \\
\text { Atas }\end{array}$ & $\begin{array}{c}\text { Frekuensi } \\
\text { Absolut }\end{array}$ & $\begin{array}{c}\text { Frekuensi } \\
\text { Kumulatif }\end{array}$ & $\begin{array}{c}\text { Frekuensi } \\
\text { Relatif }\end{array}$ \\
\hline $52-57$ & 54,5 & 51,5 & 57,5 & 4 & 4 & $11,4 \%$ \\
\hline $58-63$ & 58,5 & 57,5 & 63,5 & 3 & 7 & $8,6 \%$ \\
\hline $64-69$ & 66,5 & 63,5 & 69,5 & 6 & 13 & $17,1 \%$ \\
\hline $70-75$ & 72,5 & 69,5 & 75,5 & 8 & 21 & $22,9 \%$ \\
\hline $76-81$ & 78,5 & 75,5 & 81,5 & 9 & 30 & $25,7 \%$ \\
\hline $82-87$ & 84,5 & 81,5 & 87,5 & 5 & 35 & $14,3 \%$ \\
\hline Jumlah & 415 & 399 & 435 & 35 & & $100,0 \%$ \\
\hline
\end{tabular}

\section{Analisis Data Penelitian}

Uji Normalitas Data

Uji normalitas data dilakukan untuk mengetahui apakah sampel yang diteliti berasal dari populasi yang berdistribusi normal atau tidak.

Tabel 3. Uji Normalitas Data

\begin{tabular}{|c|c|c|c|c|}
\hline $\begin{array}{c}\text { Data } \\
\text { Sampel }\end{array}$ & $\begin{array}{c}\mathrm{L}_{\text {observa }} \\
\text { si }\end{array}$ & $\begin{array}{c}\mathrm{L}_{\text {tab }} \\
\text { el }\end{array}$ & $\begin{array}{c}\text { Taraf } \\
\text { Signifik } \\
\text { ansi }\end{array}$ & $\begin{array}{c}\text { Kesipu } \\
\text { lan }\end{array}$ \\
\hline $\begin{array}{c}\text { Pemanfa } \\
\text { atan } \\
\begin{array}{c}\text { Perangka } \\
\text { TIK }\end{array}\end{array}$ & $\begin{array}{c}0,0921 \\
15\end{array}$ & $\begin{array}{c}0,1 \\
50\end{array}$ & 0,05 & $\begin{array}{c}\text { Norma } \\
1\end{array}$ \\
\hline $\begin{array}{c}\text { Kompete } \\
\text { nsi } \\
\begin{array}{c}\text { Profesio } \\
\text { nal }\end{array}\end{array}$ & $\begin{array}{c}0,0978 \\
1\end{array}$ & 0,1 & 0,05 & $\begin{array}{c}\text { Norma } \\
1\end{array}$ \\
\hline
\end{tabular}

Berdasarkan tabel uji normalitas di atas, dapat disimpulkan bahwa sampel yang digunakan peneliti dalam penelitian ini berasal dari populasi yang berdistribusi normal. Dimana $\mathrm{L}_{0} \leq \mathrm{Lt}$ sehingga $\mathrm{H}_{0}$ diterima.

\section{Uji Homogenitas}

Berdasarkan uji homogenitas diperoleh $\mathrm{f}_{\text {hitung }} \leq \mathrm{f}_{\text {tabel }}$ atau $1,06 \leq 1,77$ dengan taraf signifikan 0,05 yang berarti $\mathrm{H}_{0}$ ditolak dan $\mathrm{H}_{1}$ diterima. Hasil tersebut menunjukan bahwa hubungan antara variabel $\mathrm{X}$ dan $\mathrm{Y}$ homogen. Artinya variabel bebas dan terikat memiliki hubungan yang positif dan signifikan.

\section{Uji Linearitas}

Sebelum uji linearitas terlebih dahulu melakukan uji analisis regresi. Ini bertujan untuk mengetahui nilai a dan $b$. Diperoleh persamaan regresi dari hasil analisis yaitu:

$$
\hat{Y}=32,7+0,56 \mathrm{X}
$$

Persamaan regresi ini membuktikan bahwa semakin tinggi peningkatan kompetensi profesional guru SD semakin meningkat pula variabel pemanfaatan perangkat TIK SeKecamatan Ruteng.

Berikut adalah tabel rekapitulasi hasil uji linearitas menggunakan SPSSversi 16.

Tabel 4. Anova

\begin{tabular}{|c|c|c|c|c|c|c|c|}
\hline & & & $\begin{array}{l}\text { Sum of } \\
\text { Squares }\end{array}$ & df & $\begin{array}{l}\text { Mean } \\
\text { Square }\end{array}$ & $\mathrm{F}$ & Sig. \\
\hline \multirow{5}{*}{$\begin{array}{l}\text { Pemanfaatan } \\
\text { Perangkat TIK . } \\
\text { Peningkatan } \\
\text { Kompetensi } \\
\text { Profesional Guru }\end{array}$} & $\begin{array}{l}\text { Between } \\
\text { Groups }\end{array}$ & (Combined & 2356,876 & 21 & 112,232 & 2,030 &, 095 \\
\hline & & Linearity & 1108,856 & 1 & $\begin{array}{r}1108,85 \\
6\end{array}$ & 20,058 &, 001 \\
\hline & & $\begin{array}{l}\text { Deviation } \\
\text { from } \\
\text { Linearity }\end{array}$ & 1248,020 & 20 & 62,401 & 1,129 & ,421 \\
\hline & \multicolumn{2}{|c|}{ Within Groups } & 718,667 & 13 & 55,282 & & \\
\hline & \multicolumn{2}{|c|}{ Total } & 3075,543 & 34 & & & \\
\hline
\end{tabular}

Dari tabel tersebut, terlihat bahwa antara variabel pemanfaatan perangkat TIK dan variabel peningkatan kompetensi profesional memiliki hubungan yang linear dan signifikan.

\section{Uji Hipotesis} Moment

Uji hipotesis korelasi Pearson Product

$$
\begin{aligned}
& = \\
& \frac{35(185396)-(2509)(2562)}{\sqrt{((35 \times 182.935)-6.295 .081)(35(190.260)-6.563 .844}} \\
& =\frac{60802}{101260737}=0.60
\end{aligned}
$$

Harga $r_{x y}=0.60$ adalah positif. Artinya hubungan antara $\mathrm{X}$ dan $\mathrm{Y}$ bernilai positif.

$$
\begin{aligned}
& \mathrm{T}_{\text {hitung }}=\frac{r \sqrt{n-2}}{\sqrt{1-r^{2}}} \\
& =\frac{0,60 \sqrt{35-2}}{\sqrt{1-0,60^{2}}} \\
& =4,31
\end{aligned}
$$


Jadi hasil perhitungan menunjukkan bahwa nilai $\mathrm{t}_{\text {hitung }}=4,31>\mathrm{t}_{\text {tabel }}=2,235$ dengan taraf signifikansi $\alpha=0,05 / 2=0,025$ (uji 2 sisi); $\mathrm{dk}=\mathrm{n}-\mathrm{k}=35-2=33$ yang berarti bahwa terdapat korelasi positif dan signifikan variabel X dan Y. Maka keputusannya $\mathrm{H} 0$ ditolak dan $\mathrm{H} 1$ diterima.

Analisis data menunjukan bahwa variabel pemanfaatan perangkat TIK dan peningkatan kompetensi profesional guru memilki pengaruh yang positif dan signifikan. Dari hasil uji homogenitas antara variabel pemanfaatan TIK dan peningkatan kompetensi profesional guru mempunyai hubungan yang homogen dimana $F_{\text {hitung }}=1,06$ dan $F_{\text {tabel }}=1,77$ pada taraf signifikansi 0,05 dengan $\mathrm{dk}(\mathrm{n}-1)$.

Hasil perhitungan menunjukan bahwa $\mathrm{F}_{\text {hitung }}=$ $1,06 \leq$ Ftabel $=1,77$, maka data homogen. Sedangkan hasil perhitungan koefisien regresi variabel Pemanfaatan perangkat TIK dan peningkatan kompetensi profesional guru diperoleh persamaan regresinya yaitu $b=0,56$ dan konstanta regresi $\alpha=32,7$ artinya bahwa semakin tinggi peningkatan kompetensi profesional guru SD semakin meningkat pula pemanfaatan perangkat TIK oleh guru SeKecamatan Ruteng.

Persamaan regresi di atas menunjukan bahwa ada pengaruh positif atau signifikan dari variabel pemanfaatan perangkat TIK terhadap variabel peningkatan kompetensi profesional guru SD. Sedangkan korelasi kedua variabel diperoleh nilai $\mathrm{rxy}=0,60$ setelah dibandingkan dengan kriteria hubungan korelasi berada pada kategori kuat. Maka tingkat hubungan pemanfaatan perangkat TIK dan peningkatan kompetensi profesional guru di Kecamatan Ruteng berada pada tingkat hubungan kuat. Setelah melakukan analisis data dengan menggunakan rumus korelasi Pearson Product Moment.

Dari hasil perhitungan $\mathrm{T}_{\text {hitung }}$ diperoleh $=$ $4,31>\mathrm{T}_{\text {tabel }}=2,235$ yang berarti bahwa terdapat korelasi positif dan signifikan antara pemanfaatan perangkat TIK dengan peningkatan kompetensi profesional guru di Kecmatan Ruteng. Selanjutnya kontribusi faktor pemanfaatan perangkat TIK terhadap peningkatan kompetensi profesional guru SD SeKecamatan Ruteng sebesar 36,05\% dan sisanya $63,95 \%$ dipengaruhi variabel lain yang tidak diteliti oleh peneliti. Dengan demikian, $\mathrm{H}_{1}$ diterima dan $\mathrm{H}_{0}$ ditolak. Maka hipotesis dari penelitian ini diterima.

\section{KESIMPULAN}

Setelah melakukan analisis data, dapat disimpulkan bahwa ada pengaruh yang positif dan signifikan antara pemanfaatan perangkat TIK terhadap peningkatan kompetensi profesional guru SD se-Kecamatan Ruteng. Hal ini dibuktikan dengan persamaan regresi yaitu $\mathrm{b}=$ 0,56 dan konstanta regresi $\alpha=32,7$ artinya bahwa semakin tinggi peningkatan kompetensi profesional guru SD semakin meningkat pula pemanfaatan perangkat TIK oleh guru seKecamatan Ruteng. Nilai $\mathrm{r}_{\mathrm{xy}}=0,60 \mathrm{~T}_{\text {hitung }}>\mathrm{T}_{\text {tabe }} \mathrm{l}$ yaitu $\mathrm{T}_{\text {hitung }}=4,31$ dan $\mathrm{T}_{\text {tabel }}=2,235$. Dengan demikian, $\mathrm{H}_{1}$ diterima dan $\mathrm{H}_{0}$ ditolak. Selanjutnya, kontribusi faktor pemanfaatan perangkat TIK terhadap peningkatan kompetensi profesional guru se-Kecamatan Ruteng sebesar $36,05 \%$ dan sisanya $63,95 \%$ dipengaruhi variabel lain yang tidak diteliti oleh peneliti. Maka hipotesis dari penelitian ini diterima.

\section{DAFTAR RUJUKAN}

Arikunto, Suharsimi. 2013. Prosedur Penelitian Suatu Pendekatan Praktik. Jakarta: Rineka Cipta.

Gita A. Kumta, et al, 2002, Capability Maturity Model A Human Perspective. Delhi Business Review, Vol 3, No1, JanuaryJune 2002.

Riduwan. 2012. Dasar-Dasar Statistika. Bandung: Alfabeta.

Rusman, D. K.,\& Riyana, C. 2011. Pembelajaran Berbasis Teknologi Informasi danKomunikasi. Jakarta: PT. RajaGrafindo Persada.

Rusti Restiani, dkk, 2014, Profil Pemanfaatan Teknologi Informasi dan Komunikasi Sebagai Media dan Sumber Belajar Oleh Guru Biologi SeJakarta Selatan, EDUSAINS, Vol VI, No 01, Tahun 2014, $50-66$ 